\title{
Cyclorefraction of healthy children in the first two years of life
}

\author{
Azzam A. Ahmed \\ Department of Surgery, College of Medicine, University of Mosul.
}

(Ann. Coll. Med. Mosul 2011; 37 (1 \& 2): 93-97).

Received: $18^{\text {th }}$ Jul 2010; Accepted: $25^{\text {th }}$ Jul 2011.

\begin{abstract}
Objectives: To provide a description of refractive errors in healthy, term-born children, aged 1 through 24 months, and to test the hypothesis that spherical equivalent becomes significantly less hyperopic and less variable with increasing age.

Methods: This is a prospective, cross-sectional design, cycloplegic retinoscopy was used to measure the refractive error in both eyes of 100 healthy, term- born children in four age groups. Spherical equivalent, cylindrical power and axis were analyzed as a function of age.

Results: Spherical equivalents of right and left eyes did not differ at any age. Hyperopia declined significantly with increasing age. The variability in spherical equivalent also decreased significantly with age. Cylindrical error of one diopter or more was found in $15 \%$ of children; the proportion with astigmatism was highest in infancy and then waned. Myopia and anisometropia were rare, occurring in $5 \%$ and $2 \%$ of the sample, respectively.
\end{abstract}

Conclusions: Significant declines in hyperopia and variability of spherical equivalent appear to be features of emmetropization. The normal prediction limits provide guidelines against which data from individual patients can be compared.

الخلاصة

هدف الدراسة: تقييم نتائج قياس الأخطاء الانكسارية للعين لدى الأطفال من عمر شهر واحد ولغاية أربعة و عشرين شهر ا،

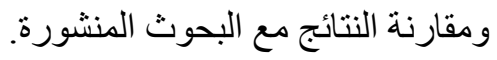
التصميم: در اسة مستقبلية مقطعية.

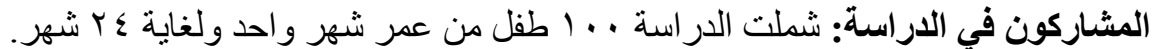

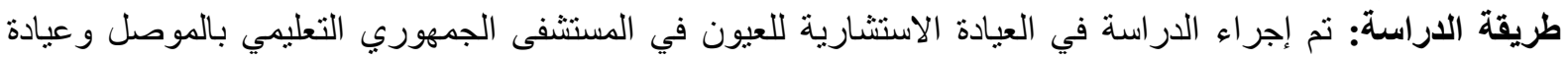

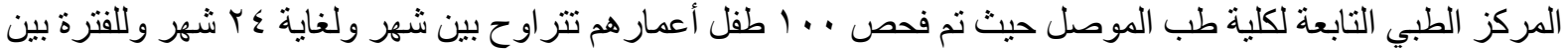

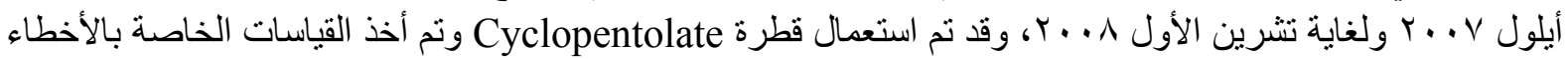
الانكسارية بواسطة جهاز Retinoscope بعد 0؛ دقيقة من استعمال القطرة المذكورة.

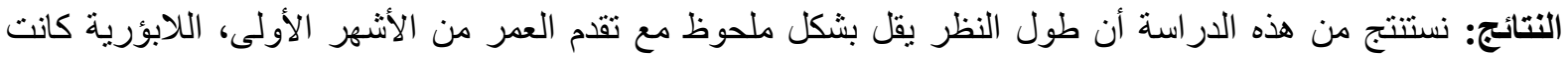

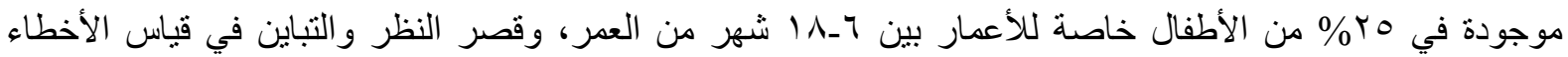

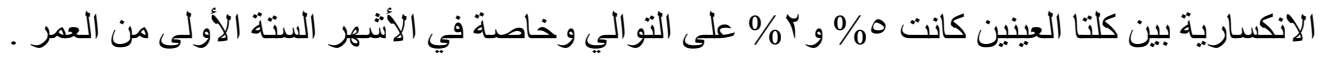

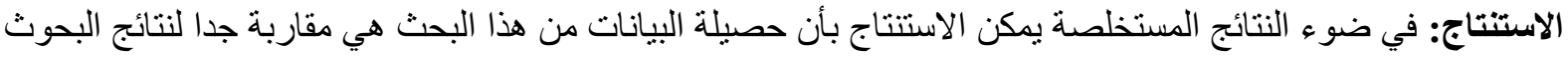

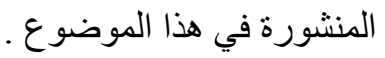


I has been long and widely recognized that infants, on average, are hyperopic, and that the hyperopia gradually decreases during infancy and early childhood. ${ }^{(1)}$

These changes in normal refractive error are presumed to reflect finely regulated eye growth $^{(1)}$, controlled at least in part by the retina ${ }^{(2,3)}$. The involved processes, known collectively as emmetropization, are accompanied by a high prevalence of astigmatism in infants. ${ }^{(4,5)}$

Despite numerous studies of refractive development, the new millennium has been entered without sufficient specification of refractive development in healthy infants and young children to support quantitative comparison with populations with disease, or to diagnose abnormal refraction in an individual youngster. ${ }^{(6)}$ The aim of this study is to provide a review of cycloplegic retinoscopy in 100 normal children. This data permits specification of normal refractive characteristics, including the limits of normal spherical equivalent for each four age groups ranging from 1 through 24 months.

\section{Methods}

This is a prospective study, refractive errors were measured in 100 healthy children aged 1 to 24 months and were categorized into four age groups:

- Group 1: age from 1 month to 6 months.

- Group 2: age from 7 months to 12 months.

- Group 3: age from 13 months to 18 months.

- Group 4: age from 19 months to 24 months.

More than half of them aged 12 months or younger. All subjects were born at term (gestational age $\geq 37$ weeks) with Apgar scores of at least 8 , had an uncomplicated neonatal course, were free of medical problems, and, by parental report, were experiencing normal development.

Of 120 children undergoing refraction, 20 were excluded because of ophthalmic abnormality (cataract $[\mathrm{n}=3$ ], disc anomaly [ $n=2$ ] or incomplete cycloplegia [ $n=10]$ as judged by ophthalmologist at the time of measurement and five miscellaneous ophthalmic problems including esotropia). Each child underwent a complete eye examination including cycloplegic retinoscopy.

Retinoscopy was performed in a dim room by streak Combi Keeler retinoscope with same hand (to avoid interexaminer variability), at least 45 minutes after instillation of $0.5 \%$ of cyclopentolate for those children below 12 months of age and $1 \%$ of cyclopentolate for those children above 12 months of age. For each eye of the 100 children, spherical equivalent, power and axis of cylinder were recorded.

Astigmatism was defined as 1.0 diopter (D) or more of cylinder. Axis of cylinder was categorized as with-the-rule (minus cylinder axis at $180^{\circ} \pm 15^{\circ}$ ), Against -the-rule (minus cylinder axis at $90^{\circ} \pm 15^{\circ}$ ) or oblique (all else) ${ }^{(8-}$ 10).

Myopia was defined as spherical equivalent of at least $0.5 \mathrm{D}$. Anisometropia was defined as difference of at least 1.0 D between eyes in spherical equivalent or cylinder. ${ }^{(7)}$ The mean spherical equivalent and the mean cylinder did not differ significantly between right and left eyes at any age. Therefore, data from the child's right eye were used to summarize the results. Preliminary analysis indicates that the spherical equivalents at each age group did not differ significantly from a normal distribution (Lilliefors test) ${ }^{(8)}$. The $95 \%$ and 99\% prediction limits were calculated for each age group (table 1). ${ }^{(8)}$ The statistical significance were accepted for tests with $\mathrm{P}$ values of no greater than 0.01 .

\section{Results}

Astigmatism was found in 25\% (25 cases) of 100. High cylindrical errors were uncommon; only 3\% (3 cases) had 2 diopters (D) or more of cylinder (figure 1).

Hyperopia represents $68 \%$ (68 cases), myopia represents 5\% (5 cases) and anisometropia represents only $2 \%$ ( 2 cases) of the sample (table 2, figure 1).

Group 2 (7 month -12 months) and group 3 (13 months - 18 months) had highest prevalence of astigmatism,12\% (12 cases), $6 \%$ (6 cases) respectively (figure 2 ). The percentage of subjects with astigmatism was not uniform across the age group. Against-the- 
rule astigmatism was more common (56\%)

than with-the-rule-astigmatism (29\%) or oblique (15\%) astigmatism. There was a significant decline in heperopia with age $(P \leq$ 0.01 ), being higher for children in group 2 (712 months) representing $40 \%$ (40 cases) then decline to $20 \%$ (20 cases) in group 3 (13-18 months) and $15 \%$ (15 cases) in group 4 (1924 months), (figure 3). Distributions of spherical equivalent appeared broader at younger age groups (table1).

Table (1): Spherical equivalent (diopters) and prediction limits*.

\begin{tabular}{|l|c|c|c|c|c|}
\hline \multirow{2}{*}{ Age, Months } & Spherical Equivalent, & \multicolumn{2}{|c|}{ 95\%Prediction Limits, D } & \multicolumn{2}{|c|}{$99 \%$ Prediction Limits, D } \\
\cline { 3 - 6 } & Mean (SD), D & Upper & Lower & Upper & Lower \\
\hline 1 & $2.20(1.60)$ & 5.51 & -1.12 & 6.66 & -2.27 \\
\hline 1.5 & $2.08(1.12)$ & 4.36 & -0.20 & 5.13 & -0.98 \\
\hline 2.5 & $2.44(1.32)$ & 5.13 & -0.26 & 6.05 & -1.17 \\
\hline 4 & $2.03(1.65)$ & 5.21 & -1.16 & 6.28 & -2.23 \\
\hline 6 & $1.79(1.27)$ & 4.39 & -0.81 & 5.27 & -1.69 \\
\hline 9 & $1.32(1.13)$ & 3.63 & -0.99 & 4.41 & -1.77 \\
\hline 12 & $1.57(0.78)$ & 3.16 & -0.01 & 3.69 & -0.55 \\
\hline 18 & $1.23(0.91)$ & 3.09 & -0.64 & 3.72 & -1.27 \\
\hline 24 & $1.19(0.83)$ & 2.89 & -0.50 & 3.47 & 1.08 \\
\hline
\end{tabular}

* $\mathrm{D}$ indicates diopters.

Table (2): Distribution of refractive errors among the age groups.

\begin{tabular}{|l|c|c|c|c|}
\hline Refractive errors & $\begin{array}{c}\text { Group 1 } \\
(1-6) \\
\text { months }\end{array}$ & $\begin{array}{c}\text { Group 2 } \\
(7-12) \\
\text { months }\end{array}$ & $\begin{array}{c}\text { Group 3 } \\
(13-18) \\
\text { months }\end{array}$ & $\begin{array}{c}\text { Group 4 } \\
(19-24) \\
\text { months }\end{array}$ \\
\hline Hyperopia & 17 & 27 & 14 & 10 \\
\hline Astigmatism & 3 & 12 & 6 & 4 \\
\hline Myopia & 3 & 2 & 0 & 0 \\
\hline Anisometropia & 2 & 0 & 0 & 0 \\
\hline
\end{tabular}

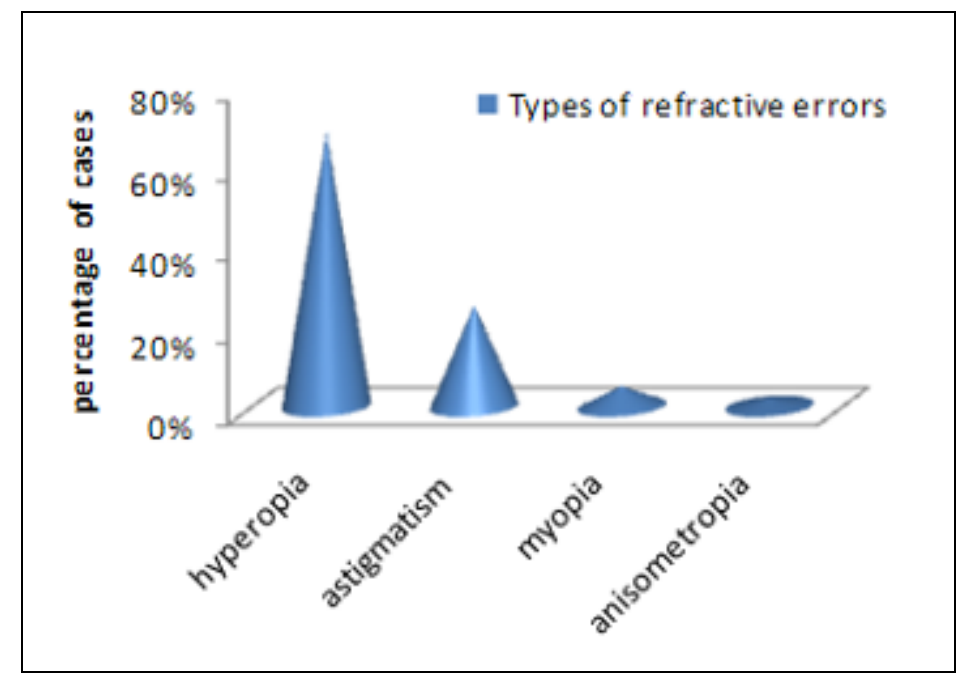

Figure (1): Percentage of refractive errors in 100 healthy full-term born children from 1-24 months. 


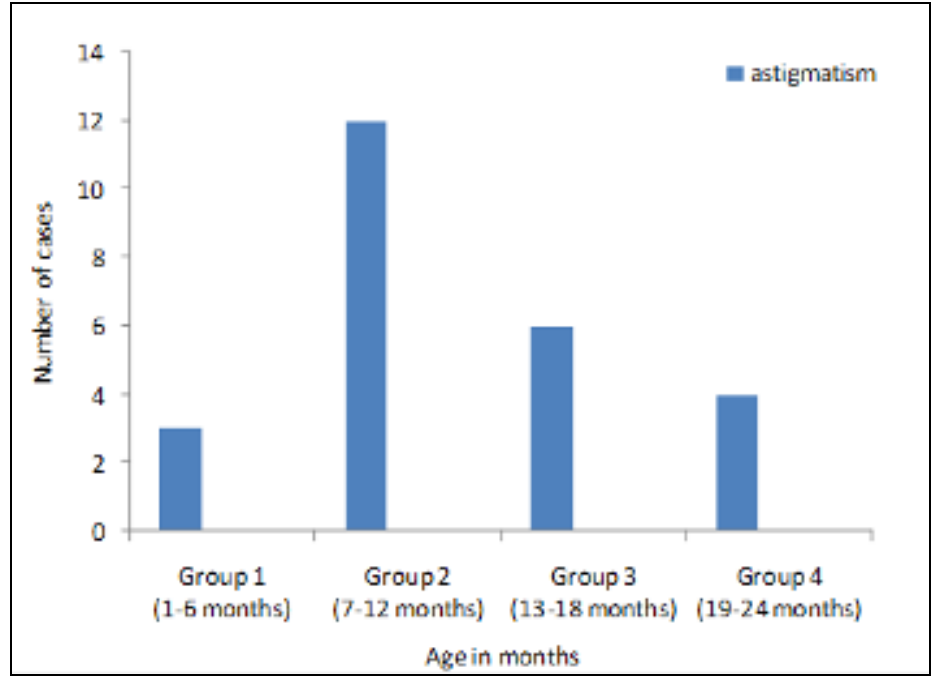

Figure (2): Number of children with astigmatism in each age group.

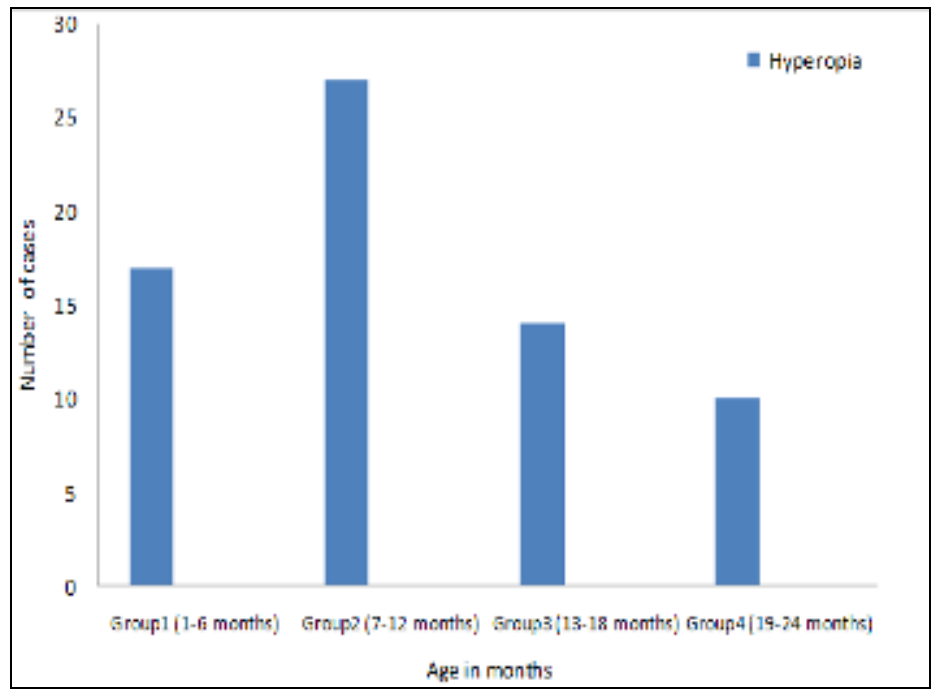

Figure (3): Number of children with hyperopia in each age group.

\section{Discussion}

The mean spherical equivalents analyzed herein and those reported in other studies, there are no conspicuous discrepancies between the results for healthy children and those with presumptively normal eyes, compared with previous studies ${ }^{(8-10)}$. We sampled more ages during the first year, when the rate of change appears to be rapid ${ }^{(7)}$. Besides gradually decreasing hyperopia, we found another feature of normal development: the significant decrease in variability of the spherical equivalent. Furthermore, as development proceeds, there is significant variation in cylindrical power that in healthy infants is determined mainly at the cornea. The application of these data pertains to diagnosis in the individual child. Data from the 100 healthy children provide a definition of the limits of normal spherical equivalent in infants and young children. The results from an individual child can be specified as within, or outside, these limits (table 1). The broad prediction interval during infancy may bear consideration when planning screening programs that depend on refraction. Given the broad prediction intervals during infancy, screening refractions at 12 months of age or older may be more efficient. Nevertheless, detection of high cylindrical errors and 
anisometropia can contribute to the diagnosis of amblyogenic factors in infancy ${ }^{(10)}$.

\section{Conclusion}

This data further define the characteristics of refractive errors in the healthy, developing eye, and so specify limits of normal refractive error at 1 through 24 months of age.

\section{References}

1. Abrahamsson M, Fabian G, Sjosstrand J. Changes in astigmatism between age 1 and 4 years a longitudinal study. $\mathrm{Br}$. J Ophthalmo.1999; 92:145-149.

2. Quinn GE, Dobson V, Kivilin J, et al. Prevalence of myopia between 3 months \& 5.5 years in preterm infants with and without retinopathy of prematurity cooperative group. Ophthalmology 1999; 105: 1292-1300.

3. Troilo D, Wallman J, The regulation of eye growth \& refractive state: an experimental study of emmetropization. Vision Res 2000; 31:1237-1250.

4. Wallman J. Retinal control of eye growth \& refraction Prog Retin Eye Res. 2002; 12: 133-153.
5. Ravioli E, Wiessel TN, Neural control of eye growth \& experimental myopia in primates In: Block $G$, Widdows $K$, eds. Ciba Foundation Symposium, New York NY: John Wiley \& Sons Inc: 2000: 22-44.

6. Hyams L, Safir A, Philpot J, et al. Studies in refraction: bias \& accuracy of retinoscopy. Ach Ophthalmol. 2001; 85:3341.

7. Mohindra I Refraction in human from birth to five years. Doc Ophthalmol 2003; 28 : 19-27.

8. Atkinson J, Braddick O, Durden $\mathrm{K}$, et al. Screening for refractive development in 69 month old infants by photorefraction. $\mathrm{Br} \mathrm{J}$ Ophthalmol. 2000; 68:105-112.

9. Larsen J. The saggital growth of the eye, Ultrasonic measurement of depth of anterior chamber from birth till puberty. Acta Ophthalmol Scand. 2003; 49: 239262.

10. Fulton $A B$, Dobson $V$, Salem $D$, et al: cycloplegic refraction in infants \& young children Am J Ophthalmol, 2000; 90:239247. 